the Acarus scabiei, had only some five years before been under the impression that ringworm was the result not of any parasitic infection but of bad feeding in schools, where, of course, it was most frequently met with. It is easy to understand how, with the comparatively scanty knowledge concerning infection available in those days, this opinion should have prevailed. Bat I think it conveys a lesson to us in so far that it indicates how difficult it is to get away
from tradition and how necessary it is that we should check our clinical observation by careful pathological investigation, and now that we have obtained a fairly accurate knowledge of the histological changes that take place in the skin how important it is that we should go back a little further and try to determine how these histological changes are brought about, how far the various micro-organisms that are found in the skin and associated with skin disease play a primary etiological part, how far they set up secondary processes, and how far they are innocuous. We must make a careful study of the modes of invasion of these different parasitic organisms, of the conditions under which they secrete irritant substances, and of the manner in which they continue to multiply or are killed off. All these are questions concerning which we have some information but about which our knowledge is as yet far from definite or complete.

As an indication of the intimate connexion between biological and pathological problems, may I be allowed for a moment to draw your attention to the work that is at present being done on the changes that take place in epithelial cells in cancer. It is stated that the nucleus of the cancer cell resembles in certain characteristic features, and especially in the arrangement of its chromatin, the embryonic cells, male and female, from which the embryo is developed. This, of course, has been denied and reaffirmed and perhaps we cannot yet consider the matter settled. But it is interesting to note that such a relationship should be suggested, especially in view of the more recent observation that Ruffer and Plimmer's cancer bodies-those minute vesicular bodies with deeply stained central points which are found near the nucleus of the cancer cell-are identical in appearance and structure with the so-called archo-plasmic vesicles of Farmer, Moore, and Walker that are found in the male, and probably in the female, embryonic cells and apparently in no other cells during the course of the life of the individual. As I have already stated, how far this will be confirmed it is yet too early to say, but it is an exceedingly interesting fact, and it behoves those who are studying these epithelial structures to keep a careful outlook for these appearances in the epidermal cells, especially where there is irritation, and, more important still, during the early or so-called precancerous stages that are now sometimes recognised and described.

Gentlemen, I am afraid I have wandered somewhat in my treatment of what to many of you is a most concise and well-defined subject and it is possible that I may have displayed my ignorance of what to many of you may be wellrecognised facts, but my aim has been rather to show how great have been the advances in general pathology and therefore in skin pathology during the last 60 or 70 years; to indicate lines along which research may be carried on in future; to draw attention to the fact that such research can only be carried out if definite provision is made for the accommodation of those who wish to carry on such researches; and finally, to point out that the therapeutic work of the physician may in the long run be helped by such researches almost as much as, or even more than, may his diagnosis. Indeed, one can conceive of no perfect system of treatment that is not preceded by an accurate knowledge of the pathological processes, primary and secondary, that are associated with the disease to be treated. The great work of this hospital is to cure but its work can never be satisfactory, and certainly not complete, unless such great opportunities as it affords for the clinical and pathological study of disease are utilised to their full. I believe, however, that your able and energetic staff, supported, advised, and helped by a capable committee of management, may add to the reputation of this hospital, and that it may be a centre from which light goes out and leading may be offered to those who are earnestly studying dermatology. There appears to be no reason why it should not, and many reasons that it should, vie with the old Hôpital St. Louis in Paris or the more recent Allgemeines Krankenhaus in Vienna in the formation of a great school of dermatology, the pupils from which shall make the influence of its teaching felt in every quarter of the medical world.

\section{REMOVAL OF A CEREBRAL TUMOUR (ENDOTHELIOMA) WHICH HAD IN- VADED THE OVERLYING CRANIAL BONE.}

By H. GILBERT BARLING, M.B. LOND., F.R.C.S. ENG, PROFESSOR OF SURGERY AT THE UNIVERSITY OF BIRMINGFAM, ETC.

With an Acoount of the Pathology of the Tumour by R. F. C. LEITH, M.B. Edin., F.R.C.P. Edin., Professor of

Pathology in the University of Birmingham.

A MALF, aged 30 years, was admitted to the General Hos. pital, Birmingham, on Nov. 21st, 1904, with symptoms pointing to cerebral tumour. He had been under the care of Dr. Edward N. Nason in the Nuneaton Hospital where he was admitted on Nov. 5th, 1903, with a history of fits confined to the right side and without loss of consciousness, the seizures commencing in the right big toe. The patient was treated with potassium iodide and during the first fire days after his admission to hospital he had five fits, all of the character above mentioned; these were repeated at intervals until May, 1904, when his condition was as follows. There were considerable dragging of the right foot and some loss of power in the grasp of the right hand; the knee-jerk on the right side was exaggerated and there was also ankle clonus on that side. Sensation to touch, heat, cold, and pain was unimpaired, muscular sense was normal, headache was severe, and there was marked optic neuritis on the left side. On May 17th, 1904, Dr. Nason trephined over the upper end of the left ascending frontal convolution. The removed bone looked dark and congested and in parts spongy ; it was somewhat adherent to the dura mater. The bleeding was so excessive and the probability of completely removing the tumour was so little hopeful that the opera. tion was abandoned. Microscopic examination of the removed bone suggested that the growth was a spindle-cell sarcoma invading and rarefying the bone.

When admitted to the General Hospital the patient stated that he had had a fit ten days previously in which he became unconscious for a short time. When he walked be dragged the right toes along the ground; the right hand was distinctly weaker than the left and sensation to touch, \&cc.,

FIG 1.

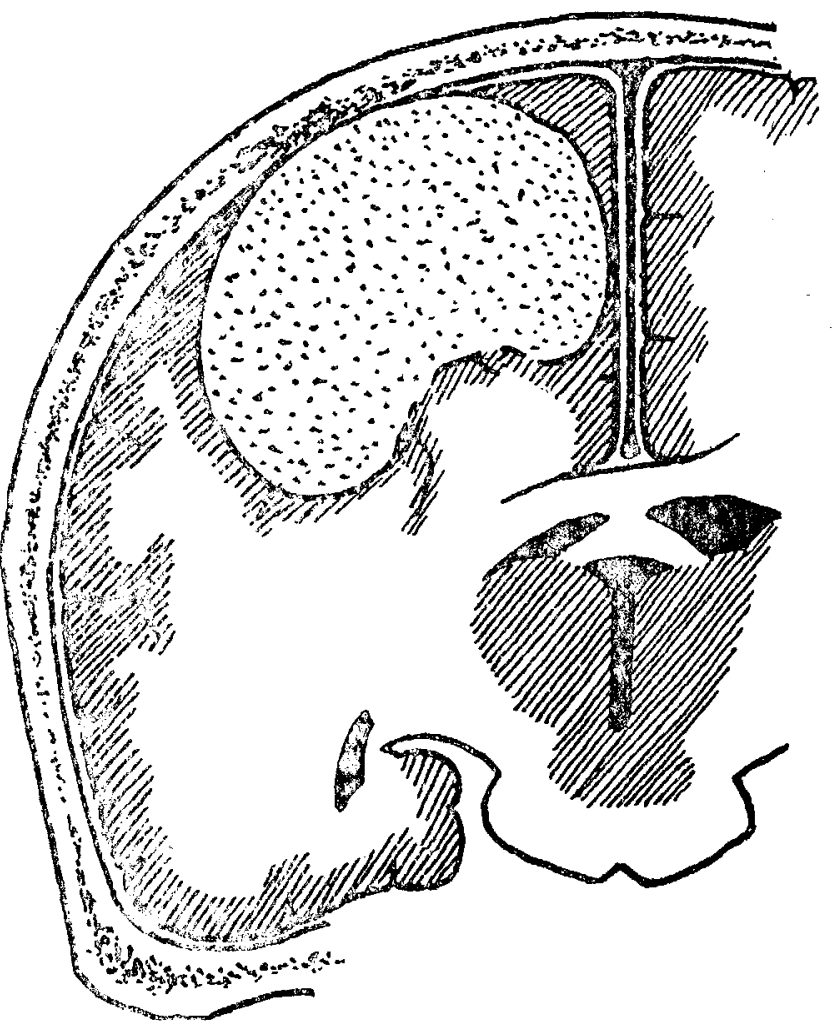

Diagram of a coronal section through tumour.

was unimpaired. As regards the reflexes, the knee-jerk on the right side was exaggerated, while that on the left side was normal; ankle clonus was present on the 
right side but not on the left. The plantar reflex been very great and the patient was quite unfit to bear any was extensor on the right side; the bicipital jerk was further manipulation. A layer of protective silk was therefore exaggerated on the right side. There was optic neuritis placed over the tumour and brain tissue, the scalp flap was in both eyes; the discs were blurred at the margins sutured, and normal salt solution was transfused. Shock was and vascular, showing only a very moderate degree of profound for the first 24 hours and then steady improvement choking. Examination of the site of operation failed to set in. There was no fit between this time and the second show anything of the nature of tumour formation such as might have been expected six months after an incomplete removal of the tumour was deferred until 11 days from the removal of a malignant growth. The patient's condition first operation as it was feared that there might be further being worse than in May, as shown by the loss of conscious- severe loss of blood which the patient was hardly in a fit ness after the fit and double optic neuritis, it was determined condition to bear. to attempt removal of his tumour.

Second operation, Dec. 16th.-The scalp flap was quickly First operation, Dec. 5th.-By means of the trephine and turned back when a large protrusion of odematous $j$ brain

FIG. 2.

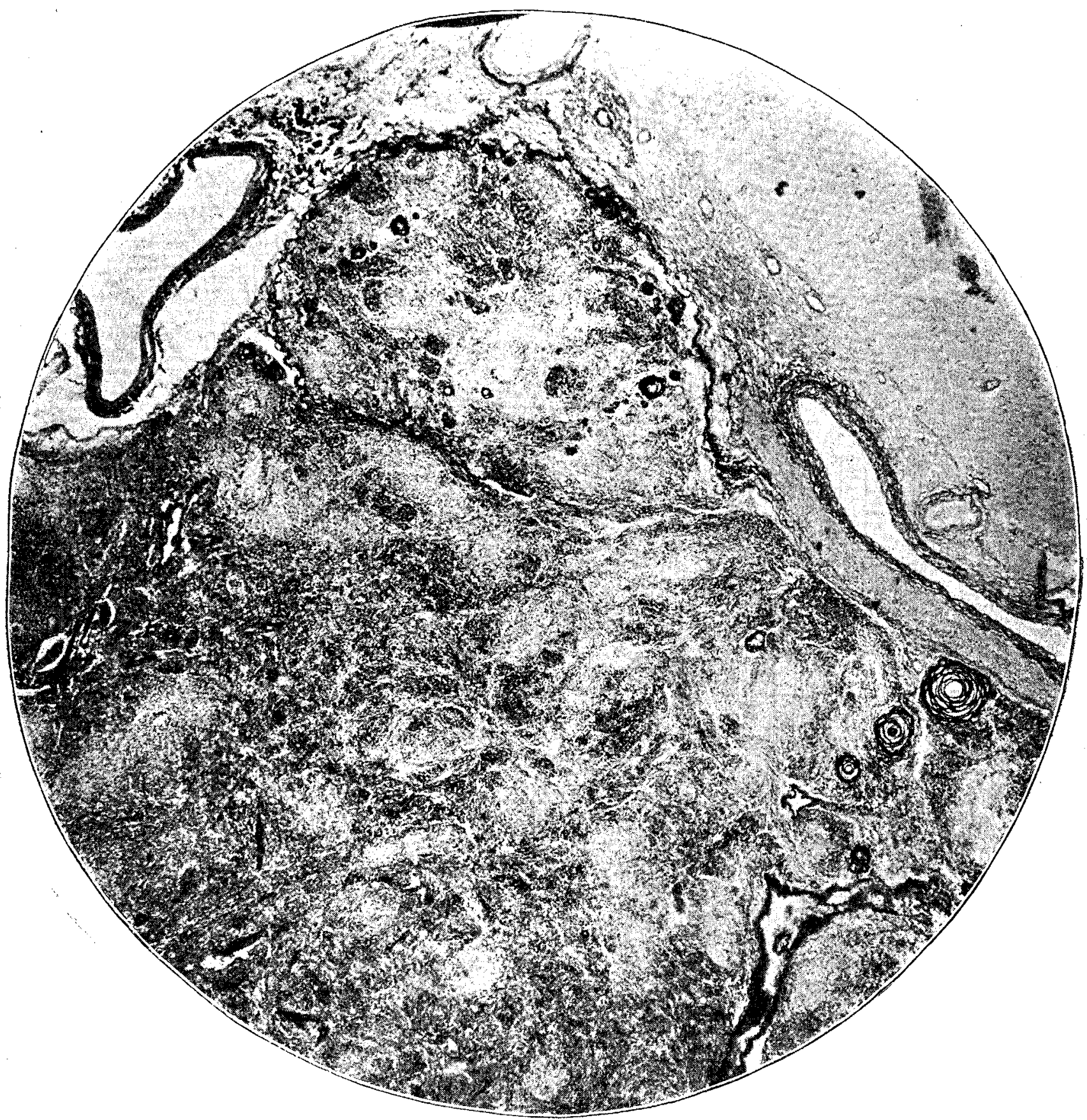

A photomicrograph $\times 30$ of the lower marginal part of the tumour, showing in the left upper part of the plate the capsule continuous with the altered pia mater, which constitntes the capsule on the under surface of the tumour. Large vessels are seen in both. Beneath the pia mater is a fragment of adherent brain cortex, seen to the right of the upper part of the field. The body of the tumour shows the general whorled arrangement of the cells and several blood-vessels with thickened walls.

forceps a large area of bone was removed over the upper part of the left motor area until an opening was made nearly four inches long and nearly three inches wide, extending to the middle line close to the longitudinal sinus. The bone was much redder than normal and it presented the appearance of a nævus condition; it was porous and adherent in places to the dura mater. The dura mater was opened and the tumour was recognised; it was of a maroon-red colour such as is usually found in myeloid sarcoma. It appeared to be imbedded in brain tissue and just coming to the surface over an area of nearly three inches by two; towards the middle line it extended right up to the falx. The loss of blood, especially from the scalp in removal of the bone, had tissue and tumour presented; puncture of this gave exit to a considerable quantity of cerebro-spinal fluid and blood. The growth was enucleated by means of a brain knife and the fingers, the hæmorrhage being very copious. The new formation appeared to be very well defined; it reached into the depth of the brain substance for about two inches and was of about the size of a small orange. A thin layer of gold leaf was inserted over the brain substance to prevent adhesion to the surface tissues and the scalp flap was sutured. Primary union was obtained after both operations; after the second there was no trouble with the gold leaf which healed in completely.

After the removal of the tumour it was found that the 
right arm was almost completely paralysed and that the growth. The patient seems bright and well and is free from right leg was also much weaker than before the operation. headache.

On Dec. 29th there was slight power of moving the right upper arm; this power gradually increased and the movements of the leg also improved. On Jan. 17th the note was as follows: "Examination of the eyes shows that all traces of optic neuritis have entirely disappeared ; patient has had no headache and no fit since operation; the power of the right arm is increasing, and the patient is improving in his power of walking."

At the present time the state of the patient is as follows. The right upper arm is well developed and the muscles move forcibly, the forearm is weak and wasted, and the ring and

Report upon the cerebral tumour and pieces of oranial bone by Dr. LeITH.-On June 23rd, 1904, a small piece of the parietal bone was received from Dr. Nason. It was thicker, more spongy, and more vascular than normal. It was prepared for microscopic examination and a report was sent on Oct. 21st to the effect that the bone showed a marked osteoporosis, the large spaces being in part filled with blood and in part with solid masses of spindle-shaped cells. These cells were much elongated and superimposed on one another in successive layers The few blood-vessels were fairly well formed. The structure and arrangement of the cells sug.

FIG. 3.

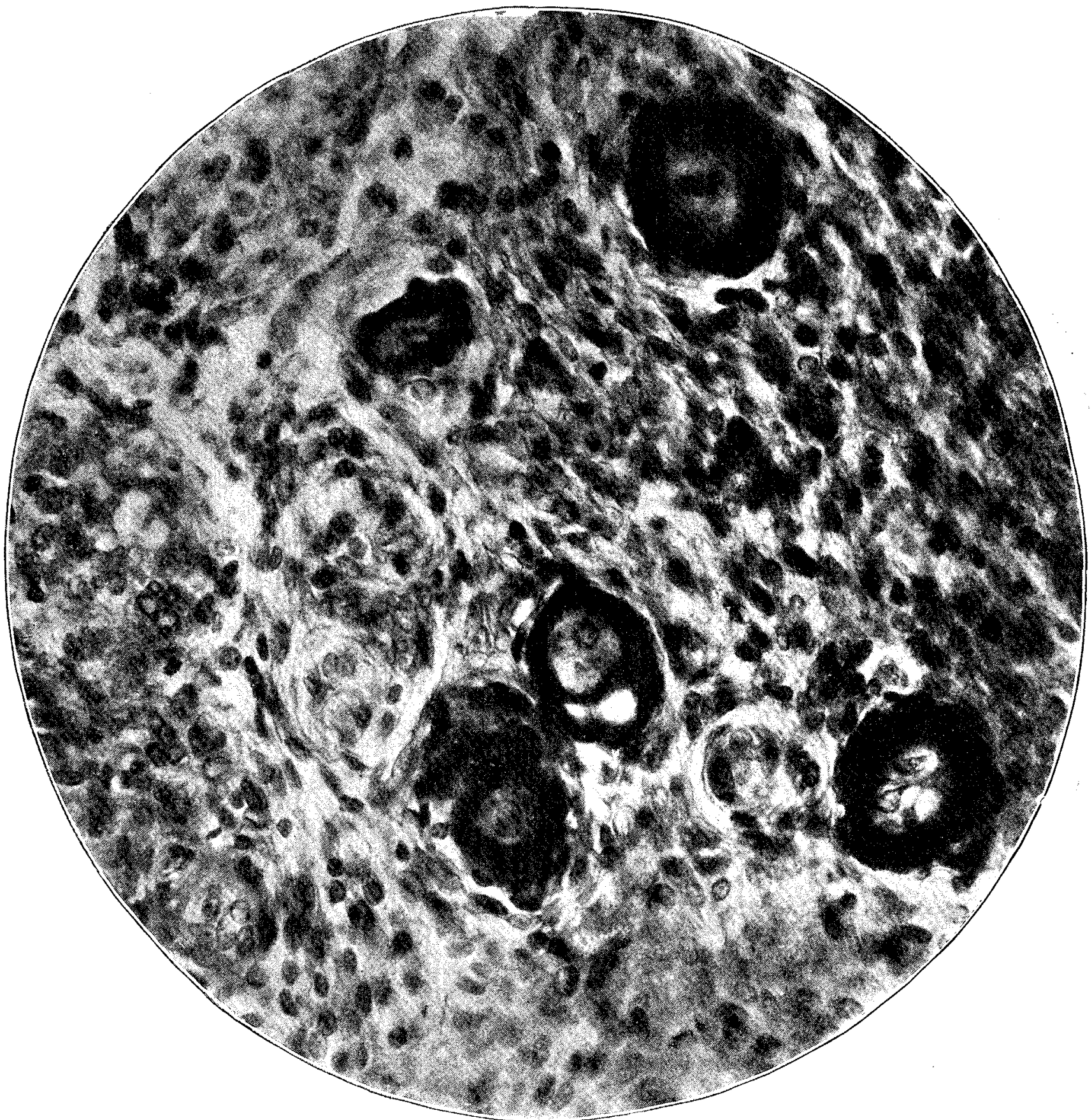

A phot micrograph $\times 570$ of a typical part of the tumour, showing its purely cellu'ar structure and the wl orled and irregular arrar gement of the spindle cells. The five dark round bodies are altered blood-vessels. Their walls are ihickered and the swollen endothelium fills the lumen more or less completely.

little fingers are specially feeble in extension. The right leg is generally weak but the patient is able to walk without assistance of any kind. The right knee-jerk is exaggerated there are ankle clonus and an extensor response in the big toe. The left knee-jerk is exaggerated, there is no clonus and neither flexor nor extensor response is obtained in the big toe. There is no optic neuritis. When the patient attempts to use his right arm and leg there is a certain amount of tremor and about every fortnight there is violent tremor of the right arm lasting about a minute but the leg is not involved; there is no fit or any lo-s of consciousness Examinaticn of the site of operation reveals the absence of hernia and there is no evidence of recurrerce of the gested some form of spindle-celled sarcoma. On Dec. 17th, 19r4, a large tumour and several trephined discs of cranial bone were received from Mr. Barling. The former, after fixation and hardening in formalin, presented the appearance of a thick disc-shaped body of an average thi $:$ kness of nearly two inches. Its upper or outer surface was somewhat convex and distinctly nodulated. Its under surface was somewhat concave with a reep depression near its centre. It measured two and three quarter inches in the larger and almost two and a half in its other diameter. It possessed a smooth capsule, distil ct and well-defined over the greater part of the tumour, particularly over its onter surface, which abutted upon the dura mater and to which it was reported to have 
been slightly adherent. The remains of these adhesions were distinctly visible as minute, thin translucent, fragmentary flakes attached to the outer surface of the capsule. 'They suggested ordinary inflammatory adhesions and not extensions of the tumour growth through its capsule. This is especially interesting in relation to the condition of the overlying bone, to be afterwards mentioned. Minute shreds of brain tissue adhered to the inner surface of the tumour giving it a slightly shaggy appearance. The tumour itself was of a firm consistence and of a whitish or whitish-yellow colour. A large vein ramified over part of its outer and marginal surface, on the latter of which an adherent band of fibrous looking tissue was seen forming a sort of rim-like thickening round the margin of the capsule. This was afterwards seen to be altered pia mater and a large pial vein ran outwards from it and communicated with the large surface vein. The relationships may be roughly reproduced by the following sketch of an imaginary coronal section passing through the skull, meninges, tumour, and brain substance.

A $V$-shaped piece extending from the upper to the under surface was cut out of the margin of the tumour close to the rim of the thickened pial tissue and prepared for microscopical examination. Sections of this showed the strong fibrous capsule bounding the tumour. Adherent to its under surface were fragments of the brain cortex showing pyramidal and other nerve cells (vide Fig. 2). The tumour substance showed everywhere an almost purely cellular structure, the cells being large and spindle-shaped. The previling arrangement was a concentric one in numerous more or less separate cylinder-like systems. The diameters of these systems varied greatly, some being very small and containing only a few layers of cells, others being larger up to sizes of 10 or 12 times as great (vide Figs. 2 and 3 ). Many of these contained a blood-vessel in their centre which in the smallest and youngest consisted solely of a single endothelial lining but in the larger and older possessed a diminished lnmen and a thickened, hyalinely swollen wall. The cells were elongated and spindle-shaped, having a distinct large nucleus and a small amount of clear protoplasm. In the concentric systems they were rolled or wrapped round a centre-in most cases a blood-ressel-like the layers of an onion. In the more irregularly shaped systems which formed the general ground substance the cells, precisely similar in character and structure, formed bundles of varying size and shape embracing the cylinders. The general arrangement thus suggested that which characterises an ordinary compact bone, where the concentric Haversian systems are held together by the irregularly shaped bundles of the interstitial systems of the bone (vide Fig. 3). But though the arrangement was somewhat similar to that of bone the structure was entirely different. It was much more purely cellular, there being very little fibrous tissue of any kind present and the cells being characteristically of a sarcomatous type. There were some slender fibrous bands passing from the capsule inwards for short distances into the tumour (vide Fig. 2), but no fibrous structures throughout the body of the tumour, except a number of roundish bodies of varying size, composed of several concentric fibrous lamellæ These bodies were very numerous and prominent throughout the whole section. (Five of them are seen in Fig. 3 ) Their origin in, and development from, blood-vessels could be quite clearly traced. The first step consisted in a thickening of one or more of the fibres of the outer coat, giving with van Giesson's stain the bright pink colour characteristic of white fibres. New and similarly thickened fibres appeared within the others and those first affected became hyalinely swollen, producing a more or less circular nodule, almost solid, or clearly composed of a number of concentric lamellæ compressing the lumen and ultimately causing its disappearance. These solid or nearly solid cylinders varied much in size from that of minute arterioles to large-siz $\alpha$ vessels, but none of them possessed any calcarrous or sandy material, such as the similarlooking bodies of a typical psammoma possess. With van Giesson's stain they gave a dark-red colour, not so bright as the young ones or so characteristic of fibrous tissue If the term psammoma be restricted to characteristic tumours containing these sandy concretions it is not applicable to this tumour which, however, shows otberwise all the cellalar structure and arrangement characteristis of that class of tumour. It is, however, clearly a sarcoma of the endotheliomatous type originating in the pia mater and should be placed somewhere near either the psammomata or the peritheliomata.
The relationship of the tumour growth to the overlying dura mater and cranial bone was carefully considered. No part of the former was removed but it was reported to have been deeply congested and somewhat adherent both to the bone outside it and the tumour inside it. The latter, on the other hand, was removed over a wide area and carefully examined. The trephined discs could be arranged in their proper places with sufficient accuracy for practical purposes and it was found that the bone over the centre of the tumour for an area of about three-quarters of an inch was slightly thickened, more spongy and more vascular than normal, while the bone surrounding this area for some considerable distance was distinctly more vascular though not apparently thickened.

The central thickened disc showed on microscopic examination the inner table to be rather extensively destroyed by tumour growth which penetrated in masses into some of the inner spaces of diploe. Smaller apparently isolated clusters of tumour cells were found as far out as the outer table. They also ran horizontally into neighbouring spaces of the diploe, only, however, for short distances from the various chief sites of the invasion. The whole of this disc of bone practically to its periphery showed the tumour invasion, but the bone immediately surrounding it did not show it. This surrounding bone had apparently escaped invasion but the spaces of its diploe for a considerable distance beyond were larger than normal and their blood-vessels increased in size and number. This increased porosity was apparentlv brought about by small irregular cells lining the spaces. No large osteoclasts could be seen and the bone appeared to be otherwise normal. The tumour masses invading the bone showed essentially the same structure as the main tumour growth itself, but the concentric cylinders of cells were not so well formed and there were none of the fibrous and hyaline blood-vessels which are so plentifully present throughout the body of the tumour.

The question arises as to how this invasion of the bone occurred. It could only have been by direct extension or by metastasis. The microscopic appearances are strongly in favour of a direct extension along the sheaths of the bloodvessels, through the capsule and through the dura mater into the bone, probably along the lines of, and subsequent to, the simple inflammatory adhesions between the capsule of the tumour and dura mater and between the latter and the bone. I hese extensions were numerous but all of them minute in size, and hence they might pass through the dense fibrous tissue of the dura mater without spreading much, if at all, into its substance. On the other hand, after penetrating the inner table of the bone their further spread would be favoured by the spongy vascular structure of the diploe. It is therefore probable that the size and extent of the bone invasion had no counterpart in the dura mater. Had the affected bone not been fully removed with the tumour, a recurrence of the growth was at least probable, and in the absence of definite facts as to the condition of the dura mater microscopically it is difficult to make any pronouncement in regard to it, but it is at least possible and perhaps probable that the invasion of the dura mater was slight and limited to the sheaths of vessels which themselves were in the process of occlusion. Hence atrophy and disappeararce of the tumour cells might be expected. That the invasion of the bone was a true metastasis is rendered improbable not only by the appearances but also by the fact that metastases are practically unknown in this class of tumour. Cerebral sarcomata in general, and in particular sarcomata of this type, are very feebly malignant, much less so, for instance, than most glinmata, so that their extirpation, wherever this is possible, offers much hope of the patient's recovery.

\section{BLOOD PRESSURE AND PIGMENTATION IN ADDISON'S DISEASE.}

By A. RENDLE SHORT, M.D., B.S., B Sc LoND., LATE HOUSE PHYSIOIAN, BRISTOL GHNRRAL HOFPITAI; SENIOR RISIINENI OFFICER, BRISTUL ROYAL INFIRMARY.

I AM indehted to Dr. George Parker for permission to put on record the following case, on which I made various observations on the blood pressure.

The patient, a man, aged 30 years, a machinist, was admitted 10 the Bristol General Hospital on July 5th, 1905 , complaining of abdominal pain and weakness and darkening 